\title{
Citizens' participation in e-government services: A Comparative Study of Pakistan \& Singapore
}

\author{
Zulfiqar Haider ${ }^{1}$, Chen Shuwen ${ }^{2}$ and Sajjad Hyder $^{3}$ \\ ${ }^{1}$ Faculty of Management and Economics, Dalian University of Technology, Dalian, 116023, China. \\ ${ }^{2}$ School of Public Administration and Law Dalian University of Technology, Dalian, 116023, China. \\ ${ }^{3}$ Department of Public Administration, University of Sindh, Jamshoro, 71000, Pakistan.
}

\begin{abstract}
It is paramount for any e-government service providers to get involve their citizen digitally \& provide better e-services platform such as cordial web portals with easy access around the clock, updated online information, better ICT infrastructure and considering them as most valued customers. However, there are many reasons behind fully adopting citizens' participation in the developing nations like Pakistan. Thus, citizen's participation can bring very fruitful results to control corruption, to judge government policies, to make better delivery of government services, cost saving by electronically, citizen empowerment, especially in decision-making and effective services in the accountability process in public and private sectors. The main purpose of this study is to find out the answers to the questions like. What are the current challenges faced by citizens while participating in e-government services in Pakistan? What the Government has done to promote citizen's participation in e-government services in all over Pakistan? At the end, a number of recommendations \& suggestions are present to the policy makers, ICT service providers, academicians and readers in order to tackle with the problems duly addressed in this comparative research study.
\end{abstract}

Keywords: e-government, citizens' participation, services, ICTs, Pakistan.

\section{Introduction}

Normally, in developed countries' e-government services have a great potential, leading government affairs in more digitally, efficiently, effectively and economically.(Alawneh, Al-Refai, \& Batiha, 2013; Venkatesh, Chan, \& Thong, 2012). The opening movements of government departments using ICT tools and its applications at large scale. Such as internet services, government web portals, mobile services, social networks that's generated innovative online services to make up good governance, strengthen existing relationship, set up new partnerships within civil society \& other stakeholders to gain the spot in a digital world by adopting e-government service.(Arduini, Belotti, Denni, Giungato, \& Zanfei, 2010). All these are the basic factors of e-government services that really overlooking towards best generates conditions for effective citizens' participation, productivity involvement and commitment any e-government system especially more need in developing countries like Pakistan. As e-government cannot involve itself unless citizens get involved in it. It is in fact important for the government to make ensure maximum citizens' participation in several online service programs otherwise, no democratic processes accomplished with the transformative power of egovernment. However, this study has focused the primary e-government development. It is also discussed, its effects, ICT outcomes with the comparison Singapore e-government services. The forthcoming citizens' improvement entrance into the digital services has made e-government by the smart deal for the government organization, fuelling worldwide implementation of such applications.(Damian, Segundo, \& Merlo, 2014).

Throughout the whole world, more often than all governments are paying great consideration in these innovative, smart technology services for their massive public. (Arduini et al., 2010). However, ICT's technologies with e-government services have adopted in most of the countries and have brought chief positive changes in all levels of managerial works for public and private sectors. The expansion of e- government services at one time depends on the ICT's access, citizens participating by using its applications, tools with moving positive citizens' attitude, trust and successful implementation that sets the authorization, impact on the modern social order. Because of systematic progress of electronic information, communication is performing a dynamic function in digital transformation in developing governments.(Horst, Kuttschreuter, \& Gutteling, 2007).

It is increasing citizen participation, adapting to the force of the knowledge base information society in a democratic state for the betterment of the citizen's. Now it has become a considerable administrative tool having a possible part to decrease the gap between what governments has done, its relations to people's daily lives. That's can help to make better citizen access to IT services and smart investment for government 
organizations, powering worldwide implementation of such application between the public and the government bodies in terms of citizen's participations, especially in public sector services.

This major dilemma of e-government services in growing nations are very unsatisfactory; at that point, there is not enough development seen towards the ICT's infrastructure, need to promote more e-culture, ineffective e-services for public, regarding less citizen's trust towards online government services. It is inconceivable for the any government in the $21^{\text {st }}$ century to become a successful without accepting these effective e-services for the citizen. It is rattling important to e-government service provider to make it friendly web access by providing the basic e-services platform i.e. innovative online channels, proper installation of ICT infrastructure in Pakistan. "As it is also noticed the use of e-government services in developing nations are extremely little only $11 \%$ on standard; compared to government practice in developed nations where they bring into play is between $70 \%-90 \%$.(Karkin \& Janssen, 2014). Nevertheless, electronic government services are still being described new form in Pakistan with its training and implementing stage especially in the public sector."

The purpose of this research find out these basic related research questions. What are the current challenges faced by citizen, while participating in e-government services? What the Government has done to promote citizen's participation in e-government services in Pakistan? How to enhance citizen participation in e-government services? On the other hands, further issues also cannot be ignore such as ICT infrastructure, eservices, proper consideration towards true adoption of e-government services, ICT's infrastructure in all over the nation at all stages. It too is facing the challenges of low computer literacy, e-culture, lack of financial resources, and international cyber law in the concern departments or ministries. In conclusion, recommendations \& suggestions are present to policy makers, ICT service providers, academician and readers.

\section{Literature Review}

Nowadays e-Government has become an important function of any regime, assisting their citizens by offering faster, easier access of information, all types of utility of government services in very efficient and benefiting manner of servicing concepts to their citizens.(Lee, Kim, \& Ahn, 2011). In spite of these few advantages of e-government, it has expanded the government responsibility for safer public access, further capabilities with success and approval of e-government scheme or plans for the future action such as an online voting scheme, tax paying, online training and license renewal system, are very dependent upon citizen readiness to study on this modernization. (Alawneh et al., 2013).

E-government programs around the globe mostly have realized since the year 2000 to improve service delivery and faster government processes. As well as connections with government stakeholders with the purpose of increasing to provide, the better e-services spending and policies in e-government services and its growth around the globe, in this view, some studies are in use to explore the implementation and diffusion of these services from the citizen perspective.(Bélanger \& Carter, 2008). The bulk of these initiatives is depending on public sector improvements expected at bringing about the most constructive delivery of public services and information to citizens, and further transparent and successful interactions with commercial enterprises, resulting in reduced corruption, and improved strength and efficiency of government communication with citizens and commercial enterprises. (Bélanger \& Carter, 2008).

The citizen's participation can take the social developmental change in the civil society with this revolution of citizen participation in self-governing \& consultative practice refers by ICT or principally by the net. (Parent, Vandebeek, \& Gemino, 2005). It aspires to support dynamic citizen's participation with the most advance technology development growing access to and make sure the availability of participation in parliamentary procedure to defend fair and efficient society and government services as an integral. Democratic government system and the official political process are essentially dependent on effective communication and informed decision making about public events along with citizens, politicians, public offices and stakeholders who may be affected by political decisions. (Damian et al., 2014).

As e-participation is referred to as a process of bringing citizens closer to government, the number of the great unwashed in this country is seized a significant issue touching the need and the capability to accept eparticipation features in the implementation of ICT. (Zheng, Schachter, \& Holzer). The Governments might try to find to encourage citizen participation in parliamentary procedure to improve the competence, recognition, and legality of political operations. (Elbahnasawy, 2014).

It is notice the uniformly important to look to at the a range of reasons for initiating citizen participation by reading off a serious question in our culture at this particular time why it is thus essential to advancing the public participation in government affair especially regarding citizen participation in basis policy making and conducting decision making. What is different from the previous participatory actions and performance in our company? For object lesson, during last 1960's and 19980 is of citizens. (Hu, Shi, Pan, \& 
Wang, 2012). There is, of course, the number of response and difficulties to give the results of those questions. At the similar occasion, the citizen participation is ethnically image as a well-off part for examination, reviving huge potential of possibilities to get fuller and get deeper the scope and consequences of the democratic decision making procedure. The citizen's participation has to be known and encourage as having a twice purpose, as the instrument for calculating the correct course and right directions, discovering the position and likely to be present and define in a sure direction. (Rorissa \& Demissie, 2010).

To implement the e-Government procedure or facilities all citizens must have the make serious efforts to put together in e-government services in their life and work. Which include all types of goals to take the freedom of information by providing the fastest \& useful information as e-Government services will provide to their citizens to switch over the information automatically given the more and better choices among an online processing and online customary techniques.(Elbahnasawy, 2014).

E-participation is the normally accepted the term that referring to ICT supported participation in process concerned with government and governance.(Arduini et al., 2010). These processes may be concerned with the administration, service delivery, decision-making and policymaking. E-participation is therefore is very closely related to e-government services and its applications as well citizens' participation. (Horst et al., 2007). The need for the term has emerged as citizen benefits and moral values have often received less attention in e-government development than those of the service providers, and the need to distinguish the roles of Citizens and customer has become clearer.(Parent et al., 2005). Many government agencies in developed countries have taken progressive steps towards the web base applications and ICT use, adding consistency to all local activities on the Internet, spreading local access and skills, opening up interactive services for local debates and increasing the participation of citizens in the promotion and management of the territory.(Sandoval-Almazan \& Gil-Garcia, 2012).

\section{Scope of the study}

This study is center along the general analysis of current challenges of e-government development regarding citizens' participation in Pakistan. The present status of citizens' participation in e-government services not fully adopted. Even, it is under development stage. It is necessary for the Government of Pakistan and all concern departments get involved with serious consideration towards this dilemma of this era.

Its further indicates in this study that e-government authorities cannot reach the winning results without citizen participation. The government should implement ICT's infrastructure; provide the best eservices with convenience, transparency, win the citizen trust, make better online transactions, updated information and cost saving speed internet services. This particular aim of the study is pointing out the main obstacles regarding citizen participation in e-government services; the survey also will serve to distinguish the root movements and current implementation challenges as pointed out above. This study, based on my best understanding that current implementation challenges of citizen's participation in e-government services can be fruitful for the future of e-government services. By this foremost research that's based on empirical research to recognize the citizens' participation performance, e-government development so, this future research path for the academician, ICT's service provider, a researcher, as considerably to the government decision makers.

\section{Significance of the study}

The results of this study are to point-out the citizen's participation in e-government services in Pakistan, to provide the recommended policy option to the government. This study will also help to prepare citizen participation on what they should act in society to turn over from e-government services as provided by the present e-Government, aid to recognize the current provision tools for the government. Citizens in finding the current implementation challenges; regarding the capacity, e-services, consultation, ICTs infrastructure, online services and engaging citizen participation in this digital world, in order to conform to new e-services requirements, changing conditions for policy making towards citizens empower in civil society, government establishments and other foundations.

\section{Theoretical basis}

The study has concerned attention towards the citizen's participation in e-government services in Pakistan. It attempts to clarify how these concepts related to focus research questions. This research has narrow down into a conceptual, theoretical framework serve as present data collection. The primary subject to study in citizen's participation in e-government services in Pakistan. Lastly, the conceptual framework has illustrated in graphical \& data forms of citation. The information will serve to more understanding, help to explain how the 
particular research works performed. (Schuppan, 2009). When an accumulation of data for this study has carried out regarding citizen's participation in e-government services can distinguish in the basic reasoning view. How the citizen's participation link to e-government services in Pakistan, how it is important for the egovernment development and current implementation challenges. For the better understand it has divided into approaching following paragraphs and roadmap model (see figure No.2).

The aim of this study is to extend through the current position of Pakistani e-government services in the setting of the viewpoint of citizen's participation. Furthermore, a purpose also to make a research in this area is to go to know the elements bearing on the current execution of e-services in Pakistan in coming future. As the Government of Pakistan has launched an e- government directorate under the Ministry of IT in 2002. To provide, the better e-services to their citizen's, to make an effective bridge between the administration and citizens. In the same context, the governments put in electronic services throughout the state, but; it could not find winning results as a whole, particularly in the public sectors. It has been known that it cannot be true implemented and successes without citizen's participation because they are the principal actors who participate and makes it enabling, strengthening and possible in democratic and decision making procedures.

The following two main goals of the Government of Pakistan regarding e-government services asunder:

To develop best ICT infrastructures, provide the smart e-government services to their citizens with efficiency and potency. Such as online transparency, accountability, and decision-making procedure in all egovernment services. Enhance the capabilities of citizen's participating with efficiently and effectively manners. Its actors carry out citizen's participation activities in e-government services. It normally characterized in this literature as different stakeholder groups (e.g., Citizens, businesspersons, researchers, and politicians). Actors are responsible, not just for taking part in the various activities but also from developing the actions related to the technologies. As for replying to the outcomes of citizen, participation always accepted in particular settings and these contextual elements, normally discussed in this research. It debated the important for the outcome of the action. As most people have misconceptions that citizen's participation can be acquired easily by ICT's just starting, implementing Information Technology and information management systems; but it is taken to lead the good enough citizen's participation in all government levels.

The citizen's participation roadmap model will help to understand all social activities, current implementation challenges and help to analysis the patterns of e-government services associated with citizen participation, its making enabling with ICT infrastructure, technology facilitates, mediates the extension or transformation of the all-natural actions. Yet, it also has observed that most citizens have no computer using capabilities, no positive attitudes toward e-governments services. Facing problems such as lack of computer education, internet knowledge, have no better experience, social network interaction, no trust on online services, high cost of internet services and ICT's awareness, infrastructure issues.

In prospect of this ground facts, the study seems to proof implementation challenges facing by the citizens regarding their participation in e-government services and need to develop a much-needed ICT's infrastructure and conceptual clarity by synthesizing relevant research. The primary aims of this study is emphasis to:

I. Identify an appropriate source body of literature in the promising field of citizen participation.

II. Logically models of citizen's participation research to increase the better understanding towards this current implementation challenges in e-government services.

III. Recognize and discuss the most important research themes and issues based on the empirical research and core literature.

IV. Citizens are the main actors to implement the e-government services in new digital government.

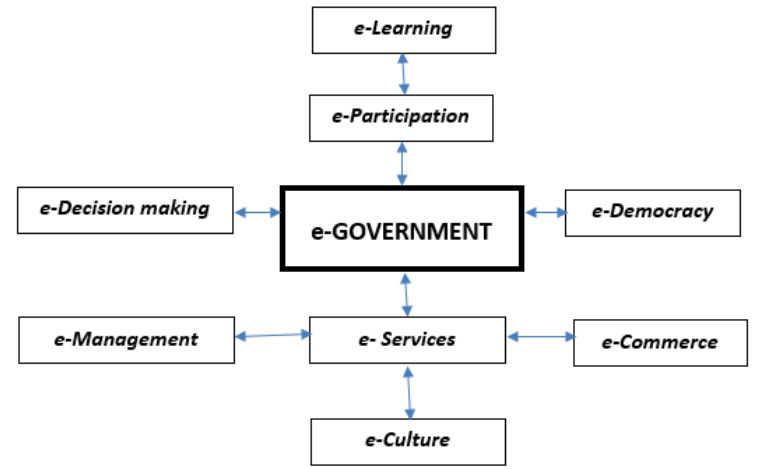

Figure \#.01 E-government association 
The knowledge of citizens as e-participation performers, particularly a more elaborate understanding of citizens' participation habits across gender, nationality, social grouping, cultural setting and realizing the functions of other participation stakeholders as under:

I. Citizens.

II. Governmental Institutions.

III. Voluntary Organizations.

IV. Political leaders.

V. Businesses Groups.

VI. Pressure Groups.

VII. Researchers.

VIII. Education Institutions.

IX. Manufacture.

X. Media.

\subsection{Citizen's desire, expectation towards e-government}

The citizens' participation is like core heart parts in the e-government activities without citizens' participation no governments can provide better results in e-government operations in the same context citizens have some desire, expectation towards the e-government services and these desires are very necessary to make them successful as for both parties' e-government and citizens'.

\subsection{It is the channel of choice}

Citizens, wants to choose the appropriate electronic channel of communication for interaction with government according to their wish. Government should ensure multi-channel service delivery, i.e. the accessibility of all communication channels, counter, letter, phone, fax, e-mail and internet.

\subsection{Transparent Public Sector}

Citizen wants where to apply to get the official, required information without any difficulties and delay. Government must guaranties one-stop-shop service delivery. Acts as one faultless entity with no wrong doors and guide citizens as they fire.

\subsection{Right's Choice of Service \& Duties}

It is very necessary that all needed information should be available on government web portal so that it easy to access to know relate information according to their desire requirement. Government ensures their responsibilities, rights of duties in all time with crystal clear and ready to provide or updated all necessary information to the citizens.

\subsection{Personalized information}

As a citizen, I am entitled to information that is complete, up to date and honest. Government supplies suitable information modified to my demand.

\subsection{Convenient Services}

Every user wants the convenient services during online payment transactions, especially giving his or her information to the government choose to offer personal data should be keep served in a protective manner. The government makes clear what books it maintains close to him or her should not use without permission.

\subsection{Wide Procedures}

Citizen wants an easy and uncomplicated means to do their work and easier procedure to recognize about the government programs, present and future work, their advancement. Government keeps itself updated all time with necessary information.

\subsection{Trust and dependability}

Citizen hopes to get great trust and confidence from government electronically capabilities in all areas of e- services. On the other hands, the government should offer the guarantees protected independence management and logical storage space of electronic documents safe for a specific time of menstruation.

\subsection{Accountability}

Citizen supposed to be as a customer and they must allow comparing services, checking online 
information, analytical thinking and calculating government results in the time, with any problem. Government should take all these dynamically producers, supplies best, and true information about its operation.

\subsection{Involvement}

All citizens require taking part in the government, presenting their role in decision-making to need to encourage their endeavor \& involvement. Government supports empowerment, ensures that the necessary information and instrument are available.

\section{The roadmap model \& methodology}

This study draws the attention towards the citizens' participation in e-government services in Pakistan and tries to explain how these concepts related to the focus research questions. This study also has narrow down into a roadmap framework serve as present data collection and represents the main findings to study in e-government services. Ultimately, the roadmap has illustrated in graphical or tabular forms of citation. The study will serve to more understanding, help to explain how the particular research works answered. When collection of data for this study has been carried out regarding citizens' participation in e-government services can be distinguished in the basic reasoning view as to how the citizens' participation link to e-government services in Pakistan. How it is important for the e-government development, its challenges for better understanding the problem. It has divided into forthcoming following roadmap model (see figure \#. 2).

The intellect of this study is to gauge out the current position of e-government services in Pakistan with the context of citizens' participation. Furthermore, other purpose is to realize a research in this area to recognize the elements bearing on the current challenges of e-services in Pakistan present and approaching in the hereafter. As the Government of Pakistan has established the e-government directorate under the Ministry of IT in 2002, to provide the better e-services to their citizens. It creates an effective bridge between the government \& citizen in the same context the governments introduce electronic services throughout the country. Unfortunately, it could not find results that are more effective as a whole, especially in public sectors; it has recognized that it cannot be true implemented, successes without citizens' participation because they are the main actors, who participate, makes it enabling, strengthening and possible in democratic world.

The following main goals of the Government of Pakistan regarding e-government services as below:

1. To develop best ICT infrastructures, to provide the smart e-government services to the citizens with efficiency \& effectiveness, such as online transparency, accountability, decision making process in all egovernment services.

2. Enhance the capabilities of citizens' participating with efficiently and effectively manners.

3. Identify appropriate source body of literature in the promising area of citizen participation;

4. Logically models of citizens' participation research to increase the better understanding towards these current challenges in e-government services.

5. Recognize and discuss the most important research themes and issues based on the empirical research and core literature. Citizens are the main actors to go through the e-government services in new digital government.

Its actors do citizen's participation actions in e-government services. These characters are usually, various stakeholder groups, citizens, businessmen, researchers, politicians and these players are responsible not only for taking part in the various activities but also from developing the activities, associated with the technologies for responding to the outcomes of citizen participation activities always accepted in particular contexts. These contextual factors normally reported in this study. To consider the important for the outcome of the activity. As most people have misconceptions that citizens' participation can be acquired easily by ICT's just starting, implementing Information Technology and information management systems; but it is taken to lead the good enough citizens' participation in all government levels. The citizens' participation roadmap model will help to understand to analysis the patterns of e-government services which are linked up with citizen participation and that's making enabling with ICT infrastructure, technology facilitates \& mediates the extension or transformation of the all-natural actions.

It also observed that most citizens have no computer using capabilities, positive attitudes toward egovernments services. Some users do not want to be a part of it, to share their information, due to several reasons. Such as lack of computer literacy, internet knowledge, has no good social networks of interaction, don't want to participate in online services, don't want to perform their role in the public decision making 
process in e-government services and so on so forth.

On the other hands, it is likewise note that the government should provide, the more proficient and easy electronic access services to their citizens with updated information in whole fields of government web portals, contents by just clicking or enter into this digital universe. However, it could not be determined in real picture in many growing states as Pakistan there is facing a number of challenges. Thus, it is essential to fulfill that gap and increase the citizen participation by making a full partnership between the governments, citizen participation. To provide the sound ICT's infrastructure, e-services, increase the literacy rate in all levels; introducing new computer learning programs for the public with motivational programs also by the assistance of NGOs, business communities, public and private sectors. Moreover, the government should ensure easy accessibility of online data to the citizens at all layers in all time. In prospect of this ground data, the study seems to proof current challenges faced by the citizens regarding their participation in e-government services and need to develop ICT infrastructure on the foundations of the conceptual clarity by synthesizing relevant research. The primary aims of this subject are therefore to:

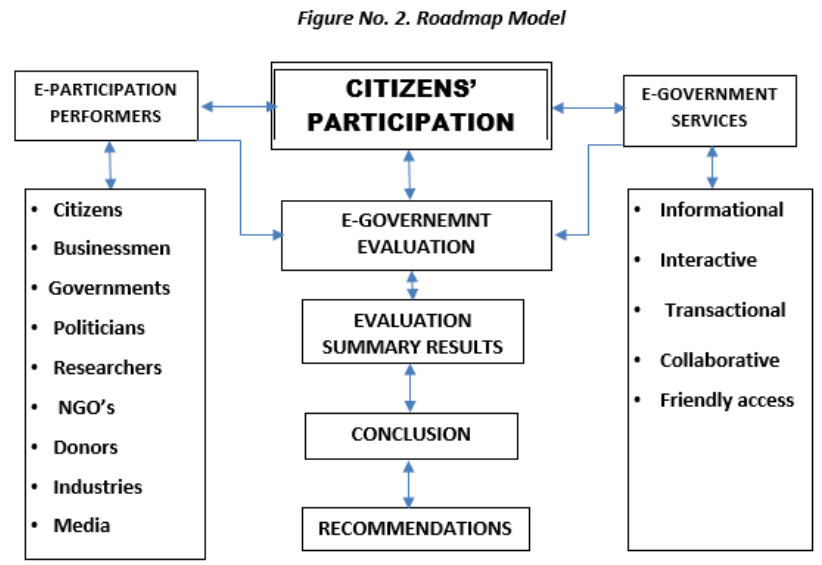

Figure No.2 Roadmap Model

\section{Methodology \& Data Analysis}

This study, based on exploratory \& qualitative data analysis. The data collected through United National survey \& World Bank, global survey reports. Furthermore, research journals, related articles, Asian development bank, government policy documentations, newspapers, government. Web portals analysis at national \& international level during (2002-2014. The study consists of re-examining, representing, categorizing, recombining the evidence to address the initial prepositions of a study. After observing and evaluation the data results are reconciled in order to enable to answer the research question will give. Exploratory research is not commonly generalize to the population, but it could give insights into the basic fabric of the given problems that needs to be address.

In this section, the gathered data, has converted into electronic graphs and relevant information, which has discussed in the light of the methodology, which already has explained in detail in methodology part during the period of (2003-2014). This study also needs to improve several suggestions regarding the collection data, that will helpful to putting in more wide-ranging. As Pakistan, is one of the developing country facing so many challenges related to socioeconomic, political, managerial, financial resources, ICT infrastructure, less internet users, IT literacy, and low industrial production.

As foremost data has obtained from the United Nation global, World Bank survey reports from 20032014. It presented in electronic graphs on yearly basis comparison between Pakistan and Singapore. It can clearly see in all graphic data performances that Pakistan is still one of the developing country that comes under mid-range scoring countries by utilization of e-government services, e-participation performances, ICT infrastructure, Human capital, and online service ranking; there is great need for more significant measures development in all these sectors.

The results of this study, also abstracted from the mentioned graphs result that the Government of Pakistan needs to identify the importance of e-government services, vital, focused to citizens' participation; ICT's infrastructure and provide friendly online services according better understanding citizens desires regarding e-services. It also finds there is big gap available between Pakistan and Singapore e-government development, indexing \& ranking (see figures no. 3, 3.1, 3.2, 3.3, 3.4, 3.5, 3.6, 3.7, 3.8, $3.9 \& 3.10$ ). It is one of the comparison pictures that, have indicated two countries' e-government presentations carried out through 
United Nations surveys ranging from 2003 to 2014. In more detail data analysis, including the comparison in each index, country also available on uniting nation survey reports.

In this age of globalization, where everybody is looking faster and reliable online services. It is also necessary for developing countries like Pakistan immediately playing its role to get involved their citizens with online participation activities, provide better e-services platform with easy accessibility. If we seek egovernment development, ranking score of Singapore throughout its well achieved compared to Pakistan that is looking so behind.

Following electronic graphs performances, explanations will help to interpret the current challenges in e-government development with actual position between two countries regarding e-government development, indexing about e-participation, online services, human capital, ICT infrastructure and citizen's participation and e-government raking.

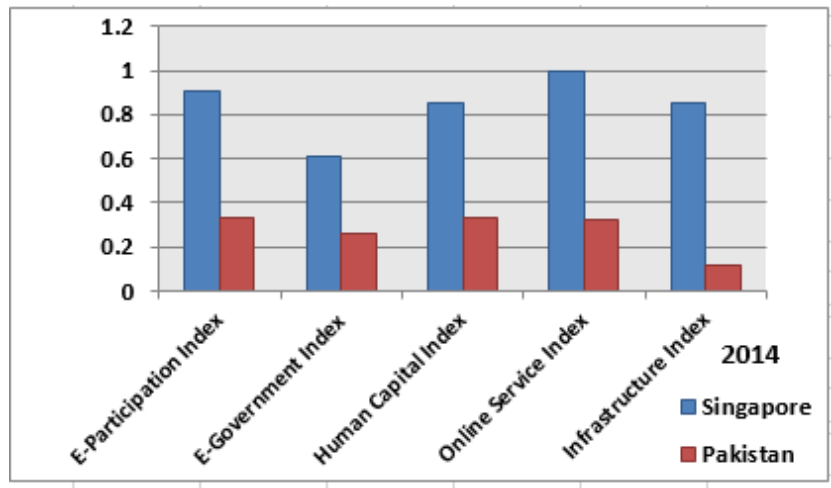

Figure No. 3

E-government development comparison between Pakistan \& Singapore [2014]

It can recognize for providing a comprehensive assessment between the two countries about egovernment development comparison between Pakistan and Singapore, throughout the years 2003 to 2014 . The Singapore is a country, which is exponentially leading the technological advancement, particularly in areas like, e-government development performances, e-participation, e-government index, human capital, online services and ICT infrastructure. The Singapore government is engaging citizens for feedback via their website, social networking tools have created an environment that politician and decision makers must adjust to and incorporate into their daily work. Singapore is doing better than Pakistan, as it is indicate through the above graphs representing 2014.

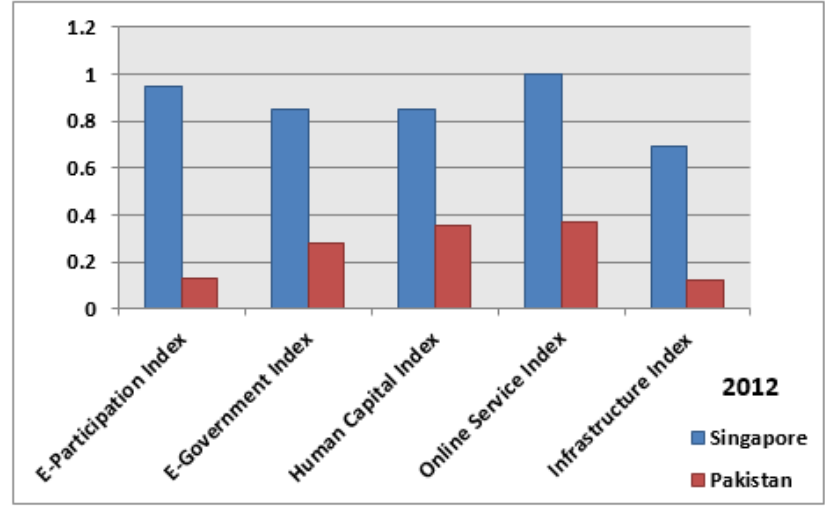

Figure No.3.1

E-government development comparison between Pakistan \& Singapore [2012]

The graph 3.1, demonstrates the statistics for the 2012, which depicts the clear rise of online service index, while gradual decline in the human capital index in Singapore as compared to statistics of 2014. Consequently, in 2012 no area of e-government, e-participation, human capital index and infrastructure got any improvement in Pakistan. It maintains stagnation in terms of policy formulation \& implementation on the part of Policy Makers in Pakistan. 


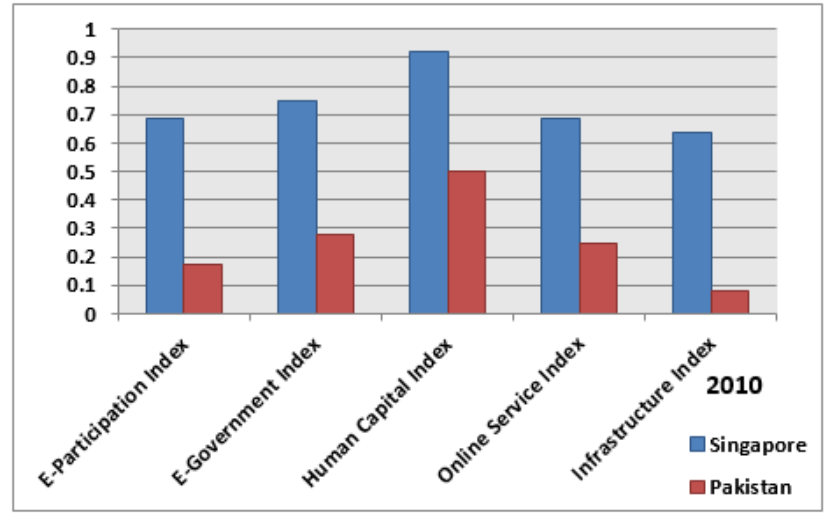

Figure No. 3.2

E-government development comparison between Pakistan \& Singapore [2010]

As of 2010, there is not substantial growth in e-government constructs like e-participation, egovernment, Human Capital index, online services index and infrastructure in Singapore, if it is compare with data available for 2008. During such intervening period that is from 2008-2010 it seems as if the ICT policies in Singapore remain slacken. However, in the same period the data for Pakistan gives even dismal picture. Until, 2010 Pakistan seems to be at very rudimentary state, when it is compare with the average usage of egovernment across the world. With infrastructure at a quite loose end, the policy makers ought to embark upon earth-breaking measures to build up new e-government \& utility installations and make extensive use to mass media to create an awareness about the economy of e-participation \& development of human capital through such application of electronic \& digital application across all the Pakistan economy.

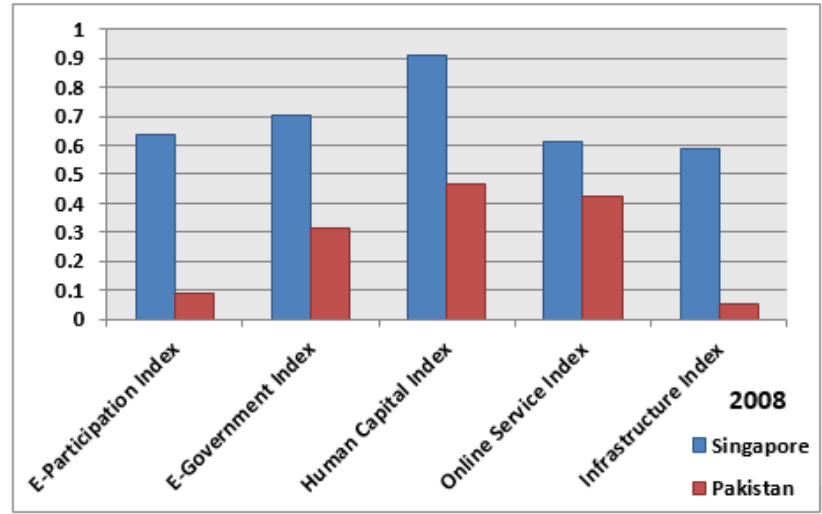

Figure No.3.3

E-government development comparison between Pakistan \& Singapore [2008]

Since 2008, Singapore has very satisfactory performance in all above graph title segments. Pakistani governments facing digitally difficulties, including e-participations, ICT infrastructure causes less internet users and personal computer usage. One of the reasons for the massive use of the e-government in Singapore is mainly due to its enhanced infrastructure and availability of latest technology. Such investment in infrastructure led to the highly technical human capital in Singapore. By 2008, the comprehensive networking through the online services the Singapore has brought its citizens within the net of technological awakening. Everywhere and every place in Singapore was endeavored to have digitized, such as shopping centers, airports, ATM machines, access to government offices by creating the Blogs and more like these adjustments have motivated the Singaporean people to take maximum benefit of it. In contrast to such development, the technological climate in Pakistan remains sluggish due to non-interest to the application of technology, weak political system and apathy on the part of bureaucracy. The concept of e-government needs to take its roots in future, if it really wants to develop into mature country and in congruence with the International Community. The policy makers should heed to the areas like producing technical people that is human capital, updating the existing digital equipment in the commercial as well official domains. Above all, mass advocacy and literacy in terms of making people realizing the urge to be efficient and cost- friendly. 


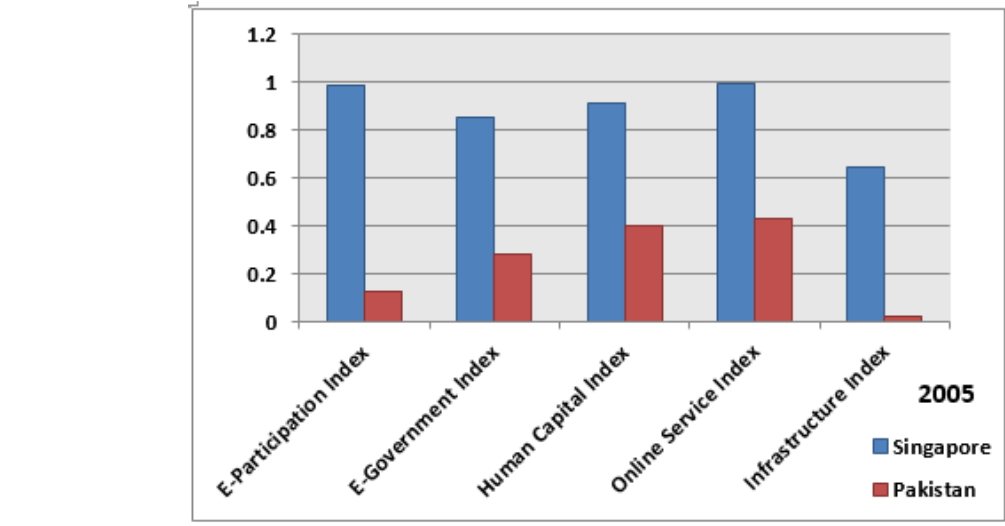

Figure No.3.4

E-government development comparison between Pakistan \& Singapore [2005]

The data for 2005 depicts effective in-place applications of online services, e-participation, and egovernment. By 2005, the Singapore has taken off in terms of proper networking of electronic applications all across Singapore. By 2005 it as attained the average usage of e-applications as a matter of policy. In contrast by 2005 Pakistan still lagging behind to install a viable infrastructure, as it almost non-existence by 2005 . However, it has some positive trends of developing human capital and initialization of online services at quite primary level, and a quite small segment of e-government incorporated.

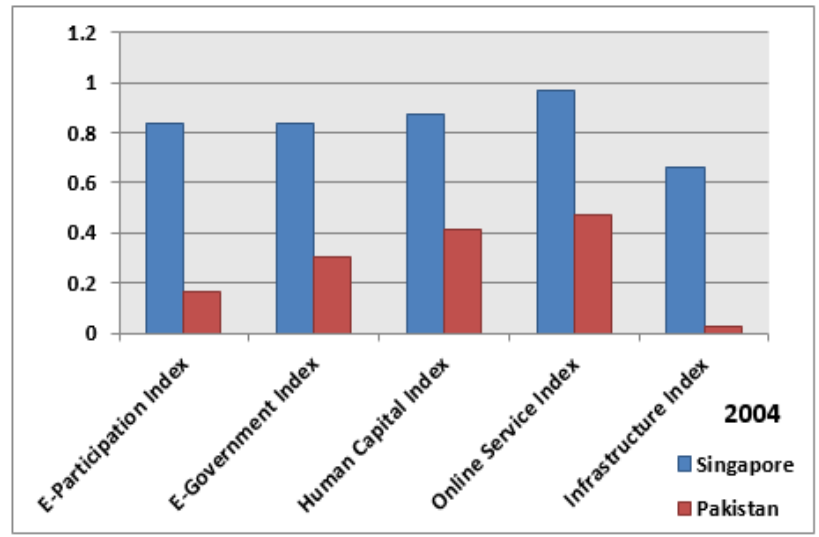

Figure No. 3.5

E-government development comparison between Pakistan \& Singapore [2004]

By 2004, as data suggest Singapore has been well on the road to technological advancement, evident by the graphical representation. Online services were on rise, along with extensive application of eparticipation \& e-government, which has, facilitates the people of Singapore to digitize their day-to-day activities, ranging from travelling on the commuter to the withdrawing of case. In stark comparison, Pakistan around 2004 was not able to develop sufficiently its infrastructure to accommodate the growing trends of technology; people were still resorting to the manual approaches to access the social, economic and political matters. Moreover, having conventional bureaucracy ill-famed with red tapes and prone to status-quo. 


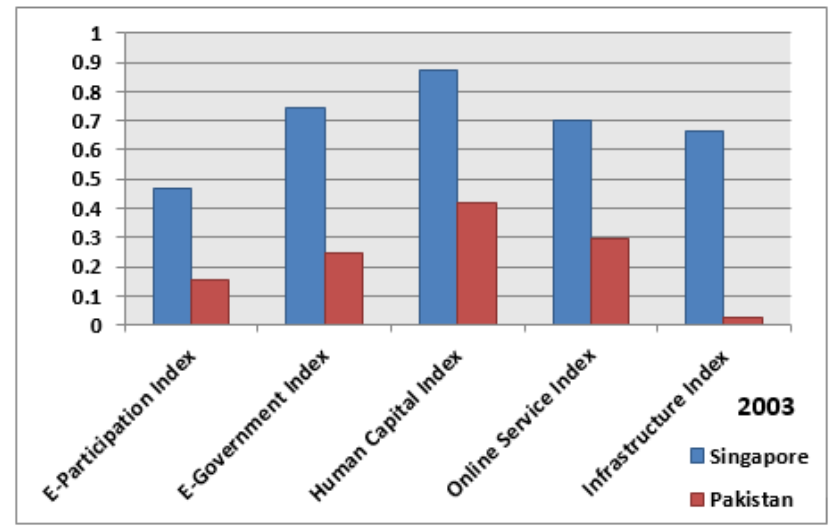

Figure No. 3.6

E-government development comparison between Pakistan \& Singapore [2003]

By 2003, Singapore resorted to Increasing broadband capacity to allow for greater speed. Need to increase more internet mobile users and devices for e-government services, need to create a trust for the public, improve the education level so that citizens may able to use of information technology and encouraging citizen participation. Around 2003, Pakistan had a kind of stagnation in terms of policy formulation \& execution, by 2003, usage of mobile phones and computers was still at primary level, and it has not taken root as the mass used utility.

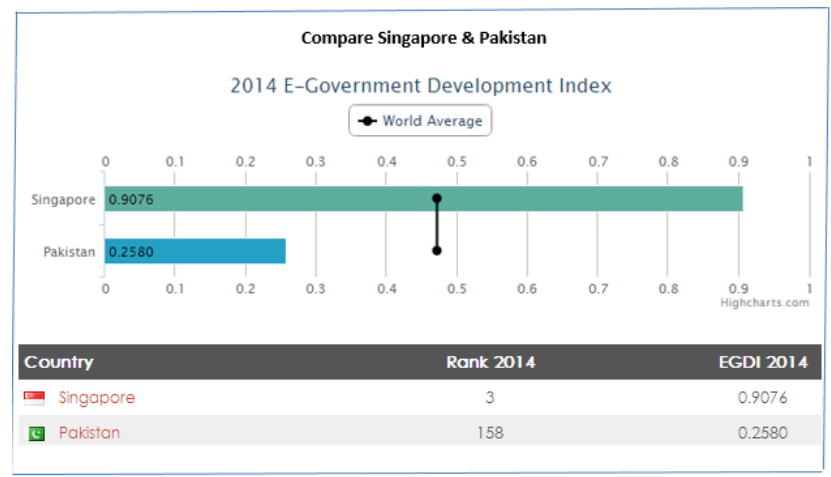

Figure No. 3.7

2014 E-government Development Index: A comparison of Singapore \& Pakistan

E-government significant and reliable measurement can offer vital notices to policy makers and authorities in the right direction. As Singapore, the government has given the diversity of approaches; include a country's economic strength, technological development and aggregate level of IT educations. Whereas Pakistani e-government must have to improve ICT infrastructure, generate more resources in shape of finance, human development and IT skills than it will be possible to increase e-government development in Pakistan.

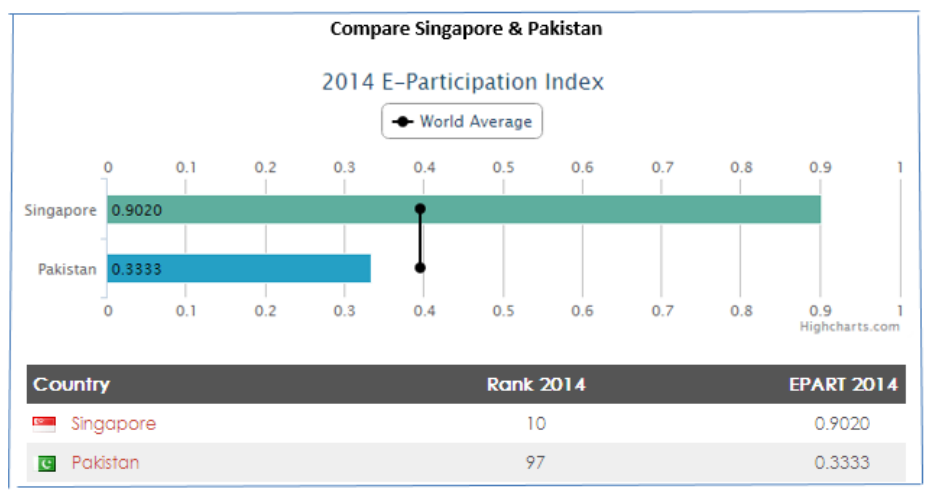

Figure No. 3.8

2014 E-participation Index: A comparison of Singapore \& Pakistan 
As it can be see that, e-participation activity remains an emerging phenomenon in many countries, but as compare to Singapore to Pakistan, it is developing in gradual manner. However, the situation remains unsatisfactory performance in e-participation. Its finding related to the disconnection between government and citizen participation as described above graph, especially in terms of Pakistan where the participation index continuum reflects that up until 2014, the Pakistani's participation is quite at lowest. It is around 03 at the scale of 10 , whereby in the same period the Singapore has risen from world average 04 scale to 09 . This clearly reflects the successful implementation of e-governmental policies on the part of Singapore by making it the high-rate high technology user \& consumer consciousness government. Pakistan needs to catch up with the global average of 04, so that it could effectively implement the tools of ICT. Further, the graph reveals that up until 2014, the Singapore ranks $10^{\text {th }}$, while Pakistan ranks $97^{\text {th }}$ in terms of e- participation. This shows lack of interest on the part of policy makers to proliferate the benefits of e-government to the public. Administrations may need to be more original about the ways in which they interact with the public; perhaps by creating integrated 'one-stop shop' portals or actively soliciting views that can used to design public services or to shape public policy. Here, Singapore is leading the e-participation indexing charge then Pakistan, as Singapore is investing more in public awareness and helping its citizens to understand benefits of e-government, which motivate the e-participation.

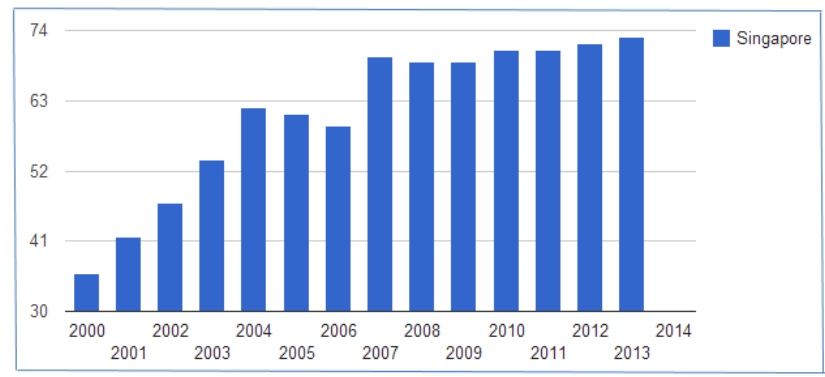

Figure No. 3.9

Singapore internet users per 100 peoples [2000- 2013]

Singapore internet users, per 100 people: For that indicator. The average value for Singapore during that period was 40.28 percent with a minimum of 0.16 percent in 2000 and a maximum of 73 percent in 2013. (Source: The World Bank provides data for Singapore from 2000 to 2013.)

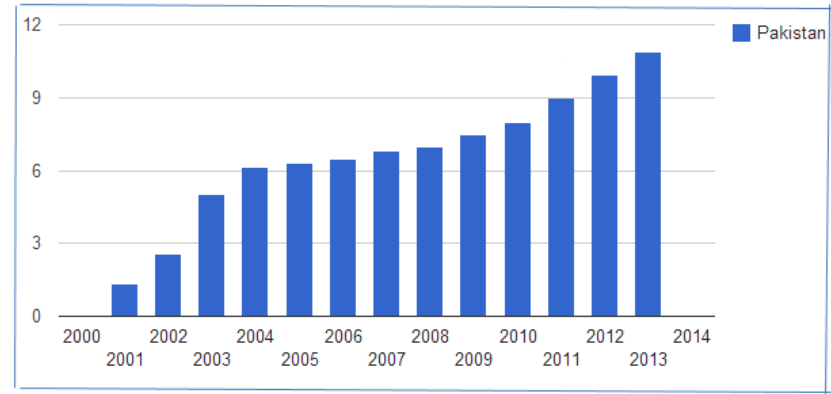

Figure No. 3.10

Singapore internet users per 100 peoples [2000- 2013]

Pakistan internet users, per 100 people: For that indicator. The average value for Pakistan during that period was 4.85 percent with a minimum of 0.05 percent in 2000 and maximum of 10.9 percent in 2013.( Source: The World Bank provides data for Pakistan from 2000 to 2013).

Above graphs $(3.9 \& 3.10)$ indicate that there is a clear technological dichotomy between Singapore \& Pakistan in terms of internet users. It further points out that increasing gap needs to be bridge in order to catch with the technological advancement of Singapore. It is indeed a quite viable challenge for the policy makers in Pakistan to seek avenues to proliferate the e-services through mass media campaign and advocacy. As Singapore is continuously heading fast from Pakistan. Its imperative the Pakistan shape up policies to bring into the technological net more subscribers on continuous basis every year. It is time that the government of Pakistan should pay more attention on ICT infrastructure, approving in all sorts of technologies in Pakistan. That will help to increase a more citizen's participation in all service sectors, which are presently available in Pakistan. 


\section{Conclusion}

The findings of this study concur with the previous research studies, research area, and its focus, even though citizen participation is yet to play a substantive part in e-government services in Pakistan. The government requires developing new ICT policy; motivate strategies with wholehearted implementation plans for encouraging the citizen's participation in E-government services, which hinders the elements of change in Pakistan. To provide more online multi-channel services, which is encouraging the ICT awareness programs, infrastructure, computer education, literacy and maximum internet connectivity for all users. There is also need, to make ensure to provide all basic e-services for all parts of the population. On the other hand, citizens also show their positive, enthusiastic, attitude towards e-participation in e-government services in Pakistan, help to develop the country by participating in the decision-making process, managerial activities accountability, and transparency in government works.

The United Nations supporting data has proved it that e-government service and citizen participation can make success together in this digital world, but it has also seen that less citizens' participation is the lack of partnership, slow communication process, less e-services, less trust on e-government services and ICT's policies in Pakistan.

With the comparison of neighboring states as listed in UN figures $(3-3.8)$, it is clear mention that performance in all areas as compared Singapore to Pakistan. There is a big gap available in e-government development, indexing throughout 2003 to 2014. The Government of Pakistan should learn a lesson from a Singapore e-government development programs and implement those success factors, including in all ICTs areas with positive consideration, which should be for the betterment of the nation and more utilization of citizens' participation in e-government services in Pakistan.

The following recommendations have two sections, one is concerned with citizen participation improvement and the second is relates implementation challenges of e-government services.

\section{Recommendation for the Government}

- Infrastructure issues should be decided on priority bases like the downfall of electricity in the whole state, required new IT equipment's in all government departments should be provided and need to developed broadband service infrastructure throughout the state with the assistance of private partnership.

- Gain the winning public policies for the purpose of electronic networks, especially between public servants and the citizenry and interest groups.

- Need to adopt massive ICT's programs and E-government service awareness campaign at all national levels.

- To supply the internet, security and enhance the trust of users, by providing basic IT facilities and all ICT information services.

- Design the cyber legislation based on the recommendation of the working group comprising IT companies, legal experts \& consumer protection copyright act.

- Get an efficient and simple government web portals in all important public dealing sectors, especially that produce better communication concurrencies among the various departments and as well as citizens.

- Provide maximum basic online transaction machines all over the state.

- Start the complain about advertising for the awareness of utilization of all government web portal services and encourage to citizens participation encouraged at all levels of services.

- Flexibility with regard to speech, acculturation, and citizens ease should also be considered and understand.

- Government should provide easier entry of information technology through the internet and telephones to the citizen's doorsteps.

- Reduce online fraud at the different point of service delivery and put through the cyber law in Pakistan.

- Increase mechanisms and implement to construct more accountability and transparency of online services in all public sectors.

- Provide ICT's platform to all type of users such as public \& private sectors, business personnel,, NGO's, and ask for help regarding ICT's implications. The Government should lunch more ICT's programs for common citizens especially, in rural areas of Pakistan its will help to increase effective citizens participation in government services. Enhancing transparency, openness, and engagement with the administration, Increasing productivity of businesses, citizens, employees, Improving efficiency in the design, delivery of government services, contributing to broader 
government economic and social outcomes.

\section{Recommendation for the Citizens}

- All stakeholders have to register their willingness in utilization of ICT programs; if they need IT training programs they get onward and make ICT enable with the work force.

- All Citizens, businesspersons, government employees have to take hold of more interest in egovernment programs and create such example for other countries by participating and using more ICT in Pakistan.

- All citizens must read that digital transactions make life more comfortable.

- Citizens can initiate their own proposals and government will count them in decision-making.

- Modernize the citizen's participation in which joined up government institution be in touch and work more effectively and efficiently.

- Develop Public-private partnerships in e-government services programs

- Stronger linkages between Academia and Industry to encourage innovation and solutions.

- Make use of online resources throughout the country like the Virtual University of Pakistan.

Necessary to read for all citizens they should pick out and accept the importance of information communication technology (ICT) by this government can execute in a more effective manner and provide better service delivery and create more jobs in this sector and aid to reduce poverty line in the nation.

\section{Reference}

[1]. Alawneh, A., Al-Refai, H., \& Batiha, K. (2013). Measuring user satisfaction from e-Government services: Lessons from Jordan. Government Information Quarterly, 30(3), 277-288. doi: http://dx.doi.org/10.1016/i.giq.2013.03.001

[2]. Arduini, D., Belotti, F., Denni, M., Giungato, G., \& Zanfei, A. (2010). Technology adoption and innovation in public services the case of e-government in Italy. Information Economics and Policy, 22(3), 257-275. doi: http://dx.doi.org/10.1016/j.infoecopol.2009.12.007

[3]. Bélanger, F., \& Carter, L. (2008). Trust and risk in e-government adoption. The Journal of Strategic Information Systems, 17(2), 165176. doi: http://dx.doi.org/10.1016/j.jsis.2007.12.002

[4]. Damian, I. P. M., Segundo, J. E. S., \& Merlo, E. M. (2014). SWOT Analysis of the Services Provided by e-government Sites in Brazil. Procedia Computer Science, 33(0), 130-135. doi: http://dx.doi.org/10.1016/i.procs.2014.06.021

[5]. Elbahnasawy, N. G. (2014). E-Government, Internet Adoption, and Corruption: An Empirical Investigation. World Development, 57(0), 114-126. doi: http://dx.doi.org/10.1016/j.worlddev.2013.12.005

[6]. Horst, M., Kuttschreuter, M., \& Gutteling, J. M. (2007). Perceived usefulness, personal experiences, risk perception and trust as determinants of adoption of e-government services in The Netherlands. Computers in Human Behavior, 23(4), 1838-1852. doi: http://dx.doi.org/10.1016/j.chb.2005.11.003

[7]. Hu, G., Shi, J., Pan, W., \& Wang, J. (2012). A hierarchical model of e-government service capability: An empirical analysis. Government Information Quarterly, 29(4), 564-572. doi: http://dx.doi.org/10.1016/i.giq.2012.04.007

[8]. Karkin, N., \& Janssen, M. (2014). Evaluating websites from a public value perspective: A review of Turkish local government websites. International Journal of Information Management, 34(3), 351-363. doi: http://dx.doi.org/10.1016/j.ijinfomgt.2013.11.004

[9]. Lee, J., Kim, H. J., \& Ahn, M. J. (2011). The willingness of e-Government service adoption by business users: The role of offline service quality and trust in technology. Government Information Quarterly, 28(2), 222-230. doi: http://dx.doi.org/10.1016/j.giq.2010.07.007

[10]. Parent, M., Vandebeek, C. A., \& Gemino, A. C. (2005). Building Citizen Trust Through E-government. Government Information Quarterly, 22(4), 720-736. doi: http://dx.doi.org/10.1016/j.giq.2005.10.001

[11]. Rorissa, A., \& Demissie, D. (2010). An analysis of African e-Government service websites. Government Information Quarterly, 27(2), 161-169. doi: http://dx.doi.org/10.1016/i.giq.2009.12.003

[12]. Sandoval-Almazan, R., \& Gil-Garcia, J. R. (2012). Are government internet portals evolving towards more interaction, participation, and collaboration? Revisiting the rhetoric of e-government among municipalities. Government Information Quarterly, 29, Supplement 1(0), S72-S81. doi: http://dx.doi.org/10.1016/j.giq.2011.09.004

[13]. Schuppan, T. (2009). E-Government in developing countries: Experiences from sub-Saharan Africa. Government Information Quarterly, 26(1), 118-127. doi: http://dx.doi.org/10.1016/j.giq.2008.01.006

[14]. Venkatesh, V., Chan, F. K. Y., \& Thong, J. Y. L. (2012). Designing e-government services: Key service attributes and citizens' preference structures. Journal of Operations Management, 30(1-2), 116-133. doi: http://dx.doi.org/10.1016/i.jom.2011.10.001

[15]. Zheng, Y., Schachter, H. L., \& Holzer, M. The impact of government form on e-participation: A study of New Jersey municipalities. Government Information Quarterly(0). doi: http://dx.doi.org/10.1016/j.giq.2014.06.004

[16]. United Nations e-Governement survey, 2003 to 2014. 